\title{
İstanbul'un Kent Topraklarında Polisiklik Aromatik Hidrokarbonların (PAHs) Birikimi ve Kökenleri Üzerine Bir Ön Araştırma
}

\author{
A Preliminary Study on Accumulations and Origins of Polycyclic Aromatic Hydrocarbons \\ (PAHs) in Urban Soils of Istanbul
}

\author{
Esra Billur BALCIOĞLU* ${ }^{* 1, a}$, Filiz Ekim ÇEVIKK ${ }^{2, b}$, Abdullah AKSU ${ }^{1, c}$ \\ ${ }^{1}$ Ístanbul Üniversitesi, Deniz Bilimleri ve İşletmeciliği Enstitüsü, Kimyasal Oşinografi Anabilim Dalı, 34134, İstanbul \\ ${ }^{2}$ İstanbul Üniversitesi-Cerrahpaşa, Adli Tıp Enstitüsü, Tıp Bilimleri Anabilim Dal, 34098, İstanbul
}

• Geliş tarihi / Received: 22.03.2018 • Düzeltilerek geliş tarihi / Received in revised form: 06.07.2018 • Kabul tarihi / Accepted: 23.07.2018

\begin{abstract}
$\ddot{O} z$
Polisiklik aromatik hidrokarbonlar (PAH), kentsel çevrede en ciddi kirletici grupları arasında yer alır. Kentsel topraklardaki PAH konsantrasyonları doğal ortam topraklarındakilere oranla 10 kat daha fazladır. Bu çalışmanın amacı İstanbul' un farklı ilçelerinden alınan toprak örneklerinde bulunan PAH'ların kontaminasyonları ve kökenleri üzerine ön verileri ortaya koymaktır. İstanbul'un yedi farklı ilçesinde toplamda 23 istasyondan 2015 yılının Temmuz ayında yüzey toprağı örneği alınmıştır. Örneklerde sekiz PAH bileşeni tayin edilmiş ve toplam konsantrasyonlar 0.12 ile 29.4 $\mu \mathrm{g} \mathrm{kg}^{-1}$ aralığında değişiklik göstermiştir. En yüksek toplam PAH $\left(\Sigma_{8} \mathrm{PAH}\right)$ konsantrasyonları yol kenarlarında ve sanayi bölgelerine yakın yerlerde tespit edilmiştir. Kökenlerin pirolitik ve/veya petrojenik olduğunu tayin etmek için fenantrenin antrasene ve florantenin pirene oranları kullanılmıştır. Yalnızca iki ilçenin tüm istasyonlarında kökenler pirolitik olarak bulunmuştur. Pirolitik kökenler motorlu taşıt egzozları, endüstriyel faaliyetler ve kömür yanmasıyla ilgilidir. Bu veriler ilerideki izleme çalışmaları için veri tabanı oluşturmakta ve PAH'larla kirlenmiş toprakların insan sağlı̆̆ üzerinde risklerin değerlendirilmesi için kullanılabilmektedir.
\end{abstract}

Anahtar kelimeler: İstanbul, Polisiklik aromatik hidrokarbonlar (PAH), Toprak kirliliği

\begin{abstract}
Polycyclic aromatic hydrocarbons (PAHs) are one group of the most serious pollutants in urban environment. Concentration of PAHs in urban soils is 10 times higher than that in natural soils. The aim of this study is to give preliminary data on contaminations and the origins of PAHs in soil samples obtained from various towns of Istanbul. Totally 23 top-soil samples collected in main urban areas in seven towns of Istanbul, Turkey in July of 2015. Samples were analyzed for eight PAHs and the total concentrations ranged from 0.12 to $29.4 \mu \mathrm{g} \mathrm{kg}{ }^{-1}$ for $\Sigma_{8} P A H s$. The highest $\Sigma P A H s$ concentrations were found at roadsides and industrial sites. The ratios of phenanthrene to anthracene and fluoranthene to pyrene were used to identify pyrolytic and petrogenic sources to determine the sources of PAHs. Only all stations of two towns in Istanbul show pyrolytic source. These sources included motor vehicle exhausts, industrial activities and coal burning. These data are a database for further monitoring studies and can be used to assess the health risk associated with soils polluted with PAHs.
\end{abstract}

Keywords: Istanbul, Polycyclic aromatic hydrocarbons (PAHs), Soil pollution

\footnotetext{
*a Esra Billur BALCIOĞLU; ebillur@istanbul.edu.tr; Tel: (0212) 45557 00; orcid.org/0000-0003-1235-9101

${ }^{b}$ orcid.org/0000-0002-1262-6452 $\quad{ }^{\mathrm{c}}$ orcid.org/0000-0003-1368-5689
} 


\section{Giriş}

Kentsel topraklar, yapılar, endüstriyel faaliyetler, trafik ve günlük yaşam gibi yoğun insan kaynaklı aktivitelerin etkisi altındadır (Rossiter, 2007; Norra ve Stüben, 2003). Şehrin ve insanların gündelik hayatının gelişimini destekleyen kentsel topraklar, şehirdeki insanlar için sağlıklı bir ortam sağlamanın yanı sıra, kentsel ekosistemin sürdürülebilir kalkınmasında önemli rol oynamaktadır (Mielke vd., 1999; PavaoZuckerman ve Byrne, 2009). Ancak özellikle gelişmekte olan bazı ülkelerde hızlı gelişen ekonomiyle birlikte, kentsel çevreler ciddi ölçüde potansiyel bir toprak kirliliği sorunu ile karşı karşıya kalmaktadır.

PAH'lar kentsel çevrede en çok bilinen kirletici gruplarındandır. Çoğunlukla karbon içeren yakıtların yanması sonucu oluşurlar (Khalili vd., 1995; Zhang vd., 2008) ve bunların çoğu mutajenik bazıları ise kanserojendir. Şehirlerdeki topraklarda artan PAH seviyeleri çoğu çalışmaya da konu olmaktadır (Trapido, 1999; Morillo vd., 2007; Wang vd., 2007). Örneğin, Wilcke (2000) kentlerdeki topraklarda bulunan PAH konsantrasyonlarının kırsal kesimdekilerdeki doğal topraklara oranla 10 kat daha fazla olduğunu rapor etmiştir. $\mathrm{Bu}$ durum kentlerdeki yoğun şehirleşme nedeniyle topraklardaki potansiyel PAH kontaminasyonu ihtimalini ve insanların $\mathrm{da}$ bu topraklara maruz kalması nedeniyle risk altında olduğu düşüncesini artırmaktadır.

Kentsel alan tanımı, trafik, sanayi, ticaret, ikamet, bahçe ve kamusal yeşil alan gibi farklı kullanım alanlarını kapsamakta, çeşitli insan faaliyetlerini ve bunların toprak kalitesi üzerindeki olas1 etkilerini ifade etmektedir (Tiller, 1992). Bazı araştırmalar kentsel çevredeki spesifik toprak kullanımlarının her zaman diğer toprak kullanımlarına göre daha yüksek PAH konsantrasyonları içerdiğini ortaya koymaktadır (Wang vd., 2007; Jiang vd., 2009; Chung vd., 2007). Örneğin, Şangay'da (Jiang vd., 2009), Dalian'da (Wang vd., 2007) ve New Orleans'da (Mielke vd., 2004) yol veya cadde kenarlarından alınan topraklarda bulunan $\mathrm{PAH}$ düzeylerinin parklardan ve yerleşim yerlerindeki topraklara oranla çok daha yüksek olduğu tespit edilmiştir. Norveç'in Bergen (Haugland vd., 2008) ve Çin' in Tianjin (Jiao vd., 2009) kentlerindeki endüstriyel alanlardan alınan topraklarda çalışılan PAH'ların diğer alanlardan alınan topraklardaki PAH'lara göre çok yüksek olduğu bulunmuştur. Buna ek olarak, kentsel toprak PAH'ları çoğu zaman bir şehrin merkezi ve / veya eski bölgelerinde yüksek seviyeler göstermektedir (Chung vd., 2007; Haugland vd., 2008). Bazı araştırmacılar şehir merkezinden uzaklaştıkça (Trapido, 1999; Wilcke vd., 2005) veya kent-ara bölge- kırsal kesim boyunca (Wang vd., 2007) PAH konsantrasyonlarında azalma olduğunu rapor etmektedirler.

Çevresel ortamda hidrokarbon bileşikleri doğal ve insan aktiviteleri (antropojenik) kaynaklı olarak bulunmaktadır. Bunlardan doğal olanlar (biyojenik olarak da adlandırılırlar), karasal organizmaların bozuşmasıyla (biyodegredasyon, biyosentez) ve diyajenetik reaksiyonlar ile ortaya çıkanlardır. Antropojenik kökenliler ise petrojenik olarak tanımlanan petrol ve işlenmiş petrol bileşikleri, rafineri tesislerinden kaynaklanan girdiler ve pirolitik olarak tanımlanan fosil yakitların yanması veya tam yanmaması ve orman yangınları sonucu meydana gelen salınımlardır (Witt, 1995).

Dünya üzerinde Asya ve Avrupa arasında yer alan mega kentlerden biri olan İstanbul, hızlı nüfus artışı, trafik ve sanayileşme nedeniyle ciddi çevre kirliliği sorunlarıyla karşı karşıya kalmaktadır. İstanbul şehri her ne kadar süregelen bir şehirleşme etkisi altında olsa da literatürde toprak kirliliği ile ilgili sınırlı sayıda rapor (Çetin vd., 2017) bulunmakla birlikte, kökenlerinin tayin edildiği bir çalışma bulunmamaktadır. $\mathrm{Bu}$ çalışmanın amacı İstanbul ilinin farklı ilçelerinden alınan toprak örneklerinde PAH konsantrasyonlarını belirlemek ve daha önce benzer çalışmalarda kullanılan oranlar yardımıyla kirliliğin kökenlerini tayin etmektir (Soclo, 1986; Sicre vd, 1987; Baumard vd., 1998) (Tablo 1). Bu oranlamalarda kullanılan bileşenler fenantren (FEN), antrasen (ANT), floranten (FLRT) ve piren (PYR)' dir.

Tablo 1. Köken tayininde kullanılan oranlar

\begin{tabular}{cccc}
\hline & FEN/ANT & FLRT/PYR & (PHE/ANT)/( FLRT/PYR) \\
\hline Pirolitik köken & $<10$ & $>1$ & $<2$ \\
Petrojenik köken & $>15$ & $<1$ & $>2$ \\
Kaynak & Soclo, 1986 & Sicre vd., 1987 & Baumard vd., 1998 \\
\hline
\end{tabular}




\section{Materyal - Metot}

Türkiye'nin kuzey batısında yer alan ve nüfus bakımından da en kalabalık ili olan İstanbul, birçok ilçesi olması nedeniyle yoğun trafik, nüfus yoğunluğu, endüstriyel faaliyet vb. durumlardan kaynaklanan ciddi çevresel kirliliğe maruz kalmaktadır. Örnekler çeşitli kirletici kaynaklarına yakın olduğu düşünülen 23 farklı noktadan yüzeyden olacak şekilde 2015 Temmuz ayında toplanmıştır. Örnekleme ilçeleri, Sarıyer, Beşiktaş, Bayrampaşa, Eyüp, Fatih, Bakırköy ve Şile olarak listelenmektedir. Örnekleme istasyonları Şekil 1'de verilmektedir.
İstanbul' un farklı ilçelerinden tahta kaşı yardımıyla alınan yüzey $(0-10 \mathrm{~cm})$ toprak örnekleri alüminyum folyoya sarılmış ve soğuk zincir altında laboratuvara getirilmiştir. Liyofilizatörde kurutulan örnekler $0.5 \mathrm{~mm}$ paslanmaz elekten geçirildikten sonra tekrar alüminyum folyoya sarılarak analize kadar $+4^{\circ} \mathrm{C}^{\prime}$ de saklanmıştır.

Çalışmada toprak örneklerinde tayin edilen $\mathrm{PAH}$ bileşikleri naftalin (NAP), asenaftilen (ACL), asenaften (AC), fenantren (FEN), antrasen (AN), floranten (FLRT), piren (PY), benzo(a)antasen (BaA)' dir.

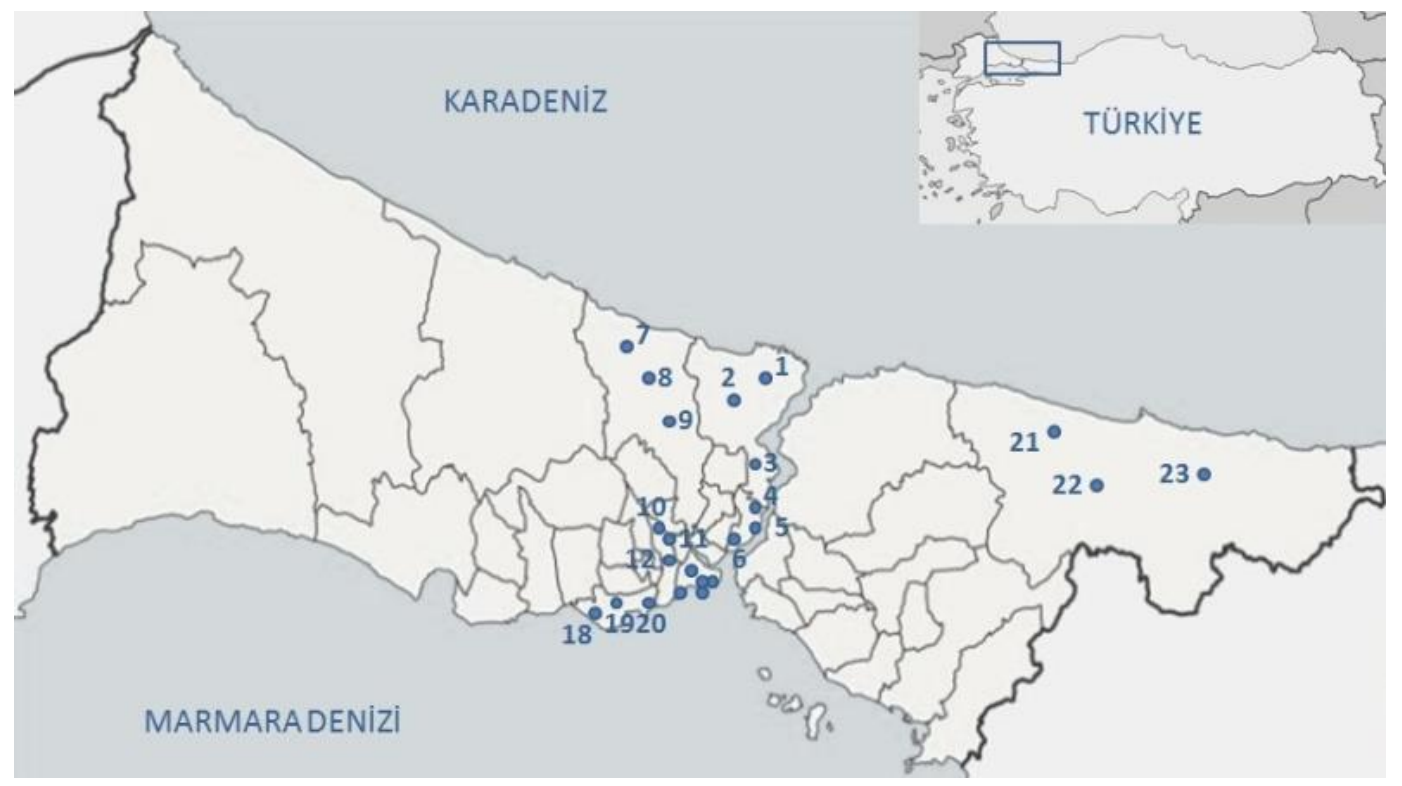

Şekil 1. Örnekleme istasyonları

Tartılıp ağırlıkları not edilen örneklerin öncelikle $200 \mathrm{~mL}$ diklorometan/hekzan karışımı $(1: 1 \mathrm{v} / \mathrm{v})$ ile 12 saat boyunca ekstraksiyonu yapılmıştır. Ekstraksiyonun ardından çözücü olarak kullanılan karışım rotary evaporatörde uçurulmuş, ardından kalıntı $1 \mathrm{ml}$ hekzanda çözünmüştür.

Hazırlanan bu çözelti cam yünü, \%3'ü kadar saf su ile deaktive edilen florisil ve susuz sodyum sülfatın pastör pipetine konulması ile hazırlanan ekstraktı temizleme düzeneğinden geçirilmiştir (Popp vd., 1997). Süzüntü yeniden uçurularak en son $1 \mathrm{ml}$ hekzan içerisinde çözünüp yüksek çözünürlüklü sıv1 kromatografisinde (HPLC) analize verilmiştir.

PAH analizlerinde 8 ayrı PAH molekülünü içeren standart stok çözeltiler hazırlanmıştır. Çalışılan standart çözeltilerin konsantrasyonları sırasıyla 1, 2, 4, 8 ve 10 ppm olacak şekilde hekzan içerisinde hazırlanmıștır. Daha sonra bu moleküllerin spektrumu alınarak cihazın kütüphanesine eklenmiştir. Çünkü örnekteki piklerin karşılaştırılması bu kütüphanedeki spektrumlara göre yapılmıştır.

PAH analizlerinde kullanılan enstrüman HP-1100 model HPLC cihazıdır. Bu HPLC sistemi 5 farklı dalga boyunda analiz imkânı sunan UV-DAD dedektörüne sahiptir. PAH analizleri için C18, 250 x $4 \mathrm{~mm}$ i.d., $5 \mu \mathrm{m}$ kolon kullanılmıştır. Kullanilan mobil faz ise metanol, asetonitril ve su karışımından oluşmaktadır. PAH analizleri $31 \mathrm{dk}$ içerisinde gerçekleştirilmiştir. Örneklerden birine ait kramotogram Şekil 2'de verilmiştir. 


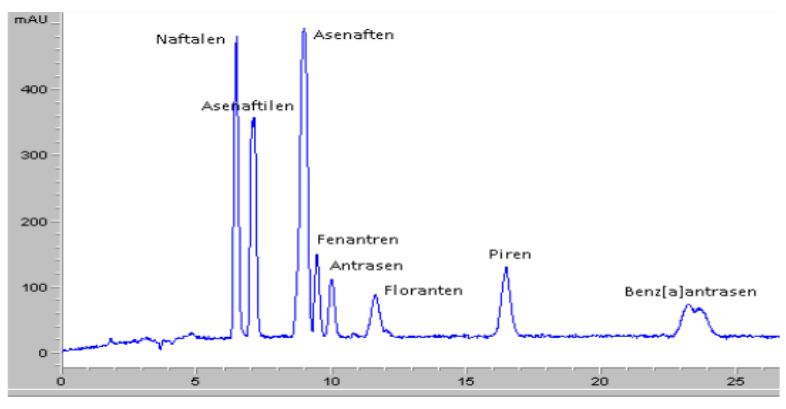

Şekil 2. 3. İstasyona ait kramotogram

\section{Bulgular ve Tartışma}

Çalışmada Temmuz 2015'te İstanbul' un 7 farklı ilçesinden olmak üzere toplam 23 istasyondan alınan yüzey toprak örneklerinde 8 adet PAH bileşeni tayin edilmiş, bulunan değerler Toprak Kirliliği ve Kontrolü Yönetmeliği (TKKY)'nde belirtilen limit değerlere göre değerlendirilmiş ve belli oranlar kullanilarak bu istasyonlardaki kirliliğin kökenleri bulunmuştur. Toplam
PAH'ların $\left(\Sigma_{8} \mathrm{PAH}\right)$ en yüksek bulunduğu ilk üç istasyonda tayin edilen bileşenlere ait konsantrasyonlar TKKY sınır değerleriyle birlikte Tablo 2'de verilmiştir.

Toplanan toprak örneklerinde tayin edilen PAH bileşenlerden çoğunun (Benzo(a)antrasen hariç) TKKY' ye göre sınır değerleri geçmediği görülmüştür.

Çalışmada en yüksek $\Sigma$ PAH $29.4 \mu \mathrm{g} / \mathrm{kg}$ ile Sarıer (3. istasyon) ilçesinde bulunmuştur (Tablo 3). Bunu 7. istasyon ve 2. istasyonlar sirasiyla $13,05 \mu \mathrm{g} / \mathrm{kg}$ ve $10,29 \mu \mathrm{g} / \mathrm{kg}$ ile takip etmiştir. En düşük $\Sigma \mathrm{PAH}$ değeri ise $0.12 \mu \mathrm{g} / \mathrm{kg}$ ile Eyüp (12. istasyon) ilçesinde tespit edilmiştir. Eyüp'ten sonra en düşük değerler Şile'de bulunmuştur. Bu ilçelerdeki değerlerin düşük bulunması diğer ilçelere göre ağır şehirleşme etkisinden nispeten uzak olmaları ile ilişkilendirilebilir.

Tablo 2. PAH sonuçlarının TKKY sınır değerleriyle kıyası (TKKY, 2010)

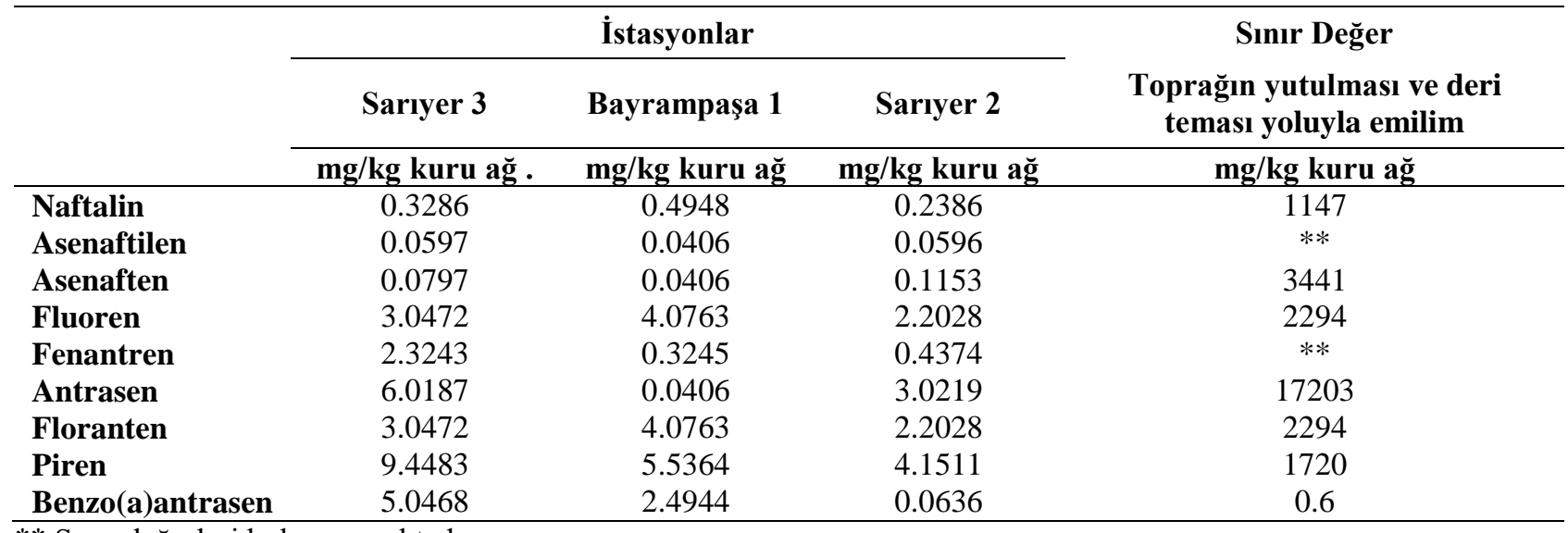

** Sınır değerleri bulunmamaktadır

Tablo 3: İstasyonlara göre $\Sigma \mathrm{PAH}$ değerleri $(\mu \mathrm{g} / \mathrm{kg})$

\begin{tabular}{cccccc}
\hline No & İstasyon & SPAH & No & İstasyon & $\Sigma$ PAH \\
\hline 1 & Sarıyer 1 & 5,99 & 13 & Fatih 1 & 0,33 \\
2 & Sarıyer 2 & 10,29 & 14 & Fatih 2 & 0,22 \\
3 & Sarıyer 3 & 29,4 & 15 & Fatih 3 & 0,21 \\
4 & Beşiktaş 1 & 0,60 & 16 & Cerrahpaşa 1 & 2,69 \\
5 & Beşiktaş 2 & 0,44 & 17 & Cerrahpaşa 2 & 1,07 \\
6 & Beşiktaş 3 & 0,30 & 18 & Bakırköy 1 & 6,52 \\
7 & Bayrampşa 1 & 13,05 & 19 & Bakırköy 2 & 0,64 \\
8 & Bayrampaşa 2 & 1,86 & 20 & Bakırköy 3 & 6,06 \\
9 & Bayrampaşa 3 & 0,47 & 21 & Şile 1 & 0,28 \\
10 & Eyüp 1 & 0,19 & 22 & Şile 2 & 0,28 \\
11 & Eyüp 2 & 0,15 & 23 & Şile 3 & 0,18 \\
12 & Eyüp 3 & 0,12 & & & \\
\hline
\end{tabular}


Aromatik bileşiklerde petrojenik ve/veya pirolitik kökenin tayininde kullanılan moleküler oranlardan FEN/ANT oranının 10'dan küçük olduğu durumlarda pirolitik kökenli bir kirlilik kaynağını, 15 'den büyük olduğu durumlarda ise petrojenik bir kirliliği işaret etmektedir (Tablo 1). FLRT/PYR oranında ise sonuç 1' den büyükse pirolitik, 1'den küçükse petrojenik bir kirlenmeyi göstermektedir. $\mathrm{Bu}$ iki oranın birbirine olan oranları da (FEN/ANT)/ (FLRT/PYR) 2' den küçükse pirolitik, 2' den büyükse petrojenik kökenli birikimler olduğu anlaşılmaktadır.

Antresen termodinamik açıdan az dayanıklı bir bileşiktir ve bu nedenle bulunduğu ortamda çok çabuk bozunmaktadır (Soclo vd., 2000). Bu bağlamda, söz konusu bileşen en yüksek 3 . istasyonda tespit edilmiştir. Örneklemenin yaz aylarında yapıldığı da düşünülürse sıcak mevsim şartlarında bu bileşenin tespit edilebilmesi örneklemeden hemen öncesinde bir girdi olduğunu düşündürmektedir. Ayrıca istasyonlarda çok düşük miktarlarda da olsa tespit edilirken, ölçüm limitlerine yakın olması yine taze bir kontaminasyon ihtimalini akla getirmektedir. Yüksek molekül ağırlı̆̆na sahip bileşikler (fluorenten, piren) ise en bol bulunanlar olup, genellikle fosil yakıtların yüksek sıcaklıkta yanma ürünü oluşan PAH'ları yansıtmaktadırlar (Gogou vd., 2000; Dahle vd., 2003). Piren termodinamik olarak flourantene göre daha dayanıklıdır.

Fluoranten ve piren, benzer şekilde fenantrene ve antrasen aynı sayıda halkaya ve molekül ağırlığına ancak farklı şekilde halka dizilişlerine sahiptir. $\mathrm{Bu}$ özellikleri de ortamda kalış sürelerini belirlenmesinde etkilidir. Flouranten ve piren yanmış petrol için, fenantren ve antrasen ise petrol ve yanma ürünleri arasında ayrım yapmakta kullanılan iyi birer indikatördürler. En yüksek flouranten ve piren değerlerinin bulunduğu 3 . ve 7. istasyonlarda bu iki bileşenin oranı, petrojenik bir kirliliği gösterse de, bu istasyona ait diğer bileşenlerin oranları ile birlikte kirliliğin hem pirolitik hem de petrojenik kaynaklı olduğu anlaşılmaktadır.

Tablo 4: İstasyonlara göre kirliliğin kökenleri

\begin{tabular}{cccccc}
\hline No & İstasyon & Köken & No & İstasyon & Köken \\
\hline 1 & Sarıyer 1 & Pirolitik & 13 & Fatih 1 & Pirolitik + Petrojenik \\
2 & Sarıyer 2 & Pirolitik + Petrojenik & 14 & Fatih 2 & Pirolitik + Petrojenik \\
3 & Sarıyer 3 & Pirolitik + Petrojenik & 15 & Fatih 3 & Pirolitik + Petrojenik \\
4 & Beşiktaş 1 & Pirolitik & 16 & Cerrahpaşa 1 & Pirolitik + Petrojenik \\
5 & Beşiktaş 2 & Pirolitik & 17 & Cerrahpaşa 2 & Pirolitik \\
6 & Beşiktaş 3 & Pirolitik + Petrojenik & 18 & Bakırköy 1 & Pirolitik \\
7 & Bayrampaşa 1 & Pirolitik + Petrojenik & 19 & Bakırköy 2 & Pirolitik \\
8 & Bayrampaşa 2 & Pirolitik & 20 & Bakırköy 3 & Pirolitik \\
9 & Bayrampaşa 3 & Pirolitik + Petrojenik & 21 & Şile 1 & Pirolitik \\
10 & Eyüp 1 & Pirolitik & 22 & Şile 2 & Pirolitik + Petrojenik \\
11 & Eyüp 2 & Pirolitik & 23 & Şile 3 & Pirolitik \\
12 & Eyüp 3 & Pirolitik & & & \\
\hline
\end{tabular}

1., 4., 5., 8.,10., 11., 12., 18., 19., 20., 21., 23. istasyonlardan alınan örneklerdeki kirlilik kullanılan oranlara göre pirolitik olsa da diğer istasyonlardaki kirliliğin kaynağının pirolitik+petrojenik olduğu ortaya çıkmaktadır. Genel olarak tüm istasyonlarda kirliliğin kaynağı pirolitik veya pirolitik+petrojenik olarak belirlenmiştir (Tablo 4). Yalnızca petrojenik kökenli kirliliğin olduğu bir istasyon bulunmamaktadır. Pirolitik+petrojenik kaynaklı kirliliğin olduğu bölgelerin hem antropojenik etkisi altında olmasının (yol kenarları, endüstri yakını bölgeler vs.) yanı sıra, tüm istasyonlarda mutlaka pirolitik kökenin bulunması karasal ortamda sürekli mevcut olan bir biyolojik bozunmaya (biyodegredasyon) işaret etmektedir.

\section{Sonuçlar}

$\mathrm{Bu}$ çalışmada İstanbul' un farklı ilçelerinde bulunan park ve bahçelerdeki topraklardan alınan örneklerde PAH bileşenlerinin konsantrasyonları ve bu bileşenlerin birbirine oranları kullanılarak kontaminasyonun kökeninin değerlendirilmesi amaçlanmıştır. Bu şekilde belirlenen istasyonlardan alınan örneklerdeki konsantrasyonlara ve oranların kullanılarak yapılan hesaplamalara göre kirlilik kaynağının pirolitik ve pirolitik + petrojenik olduğu sonucuna varılmıştır. $\mathrm{Bu}$ 
istasyonların yakınlarında bulunan yol ve caddelerin trafiğginden etkilendiği düşünülmektedir. Söz konusu park ve bahçelerin sosyal amaçlı kullanıma özellikle de çocukların kullanımına açık olması durumu ile bu alanlardaki toprakların doğrudan deriye temas etmesinin zamana bağlı olarak risk oluşturabileceği açıktır. Bu nedenle çocukların kullanımına açık olan bu bölgelerdeki topraklara fazla temas edilmemesi konusunda ebeveynleri bilinçlendirmek toplum sağlı̆̆1 yararına olacaktır.

\section{Kaynaklar}

Baumard, P., Budzinski, H., Michon, Q., Garrigues, P., Burgeot, T. ve Bellocq, J., 1998. Origin and bioavailability of PAHs in the Mediterranean Sea from mussel and sediment records, Estuarine, Coastal and Shelf Science, 47, 77-90.

Cetin, B., Ozturk, F., Keles, M. ve Yurdakul, S., 2017. PAHs and PCBs in an Eastern Mediterranean megacity, Istanbul: Their spatial and temporal distributions, air-soil exchange and toxicological effects, Environmental Pollution, 220, 1322-1332.

Chung M.K., Hu R., Cheung, K.C. ve Wong, M.H., 2007. Pollutants in Hong Kong soils: polycyclic aromatic hydrocarbons, Chemosphere, 67, 464-473.

Dahle, S., Savinov, V.M., Matishov, G.G., Evenset, A. ve Naes, K., 2003. Polycyclic aromatic hydrocarbons (PAHs) in bottom sediments of the Kara Sea shelf, Gulf of $\mathrm{Ob}$ and Yenisei Bay, The Science of the Total Environment, 306, 57-71.

Gogou, A., Bouloubassi, I. ve Stephanou, E.G., 2000. Marine organic geochemistry of The Eastern Mediterranean, 1. Aliphatic and polyaromatic hydrocarbons in Cretan Sea surficial sediments, Marine Chemistry, 68, 265-282.

Haugland, T., Ottesen, R.T. ve Volden, T., 2008. Lead and polycyclic aromatic hydrocarbons (PAHs) in surface soil from day care centres in the city of Bergen, Norway, Environmental Pollution, 153, 266-272.

Jiang, Y.F., Wang, X.T., Wang, F., Jia, Y., Wu, M.H., Sheng, G.Y. ve Fu, J.M., 2009. Levels, composition profiles and sources of polycyclic aromatic hydrocarbons in urban soil of Shanghai, China, Chemosphere, 75, 1112-1118.

Jiao, W., Lu, Y., Li, J., Han, J., Wang, T., Luo, W., Shi, Y. ve Wang, G., 2009. Identification of sources of elevated concentrations of polycyclic aromatic hydrocarbons in an industrial area in Tianjin, China, Environmental Monitoring Assessment, 158, 581-592.

Khalili, N.R., Scheff, P.A. ve Holsen, T.M., 1995. $\mathrm{PAH}$ source fingerprints for coke ovens, diesel and gasoline engines, highway tunnels, and wood combustion emissions, Atmospheric Environment, 29, 533-542.

Mielke, H.W., Gonzales, C.R., Smith, M.K. ve Mielke, P.W., 1999. The urban environment and children's health: soils as an indicator of lead, zinc, and cadmium in New Orleans, Louisiana, USA, Environmental Research Section A, 81,117-129.

Mielke, H.W., Wang, G., Gonzales, C.R., Powell, E.T., Le, B. ve Quach V.N., 2004. PAHs and metals in the soils of inner city and suburban New Orleans, Louisiana, USA, Environmental Toxicology and Pharmacology, 18, 243-247.

Morillo, E., Romero, A.S., Maqueda, C., Madrid, L., Ajmone-Marsan, F., Grcman, H., Davidson, C.M., Hursthouse, A.S. ve Villaverde, J., 2007. Soil pollution by PAHs in urban soils: a comparison of three European cities, Journal of Environmental Monitoring, 9, 1001-1008.

Norra, S. vecStübe, D., 2003. Urban soils, Journal of Soils and Sediments, 3: 230-233.

Pavao-Zuckerman, M.A. ve Byrne, L.B., 2009. Scratching the surface and digging deeper: exploring ecological theories in urban soils, Urban Ecosystems, 12, 9-20.

Popp, P., Keil, P., Möder, M., Paschke, A. ve Thuss, U., 1997. Application of accelerated solvent extraction followed by gas chromatography, high-performance liquid chromatography and gas chromatographymass spectrometry for the determination of polycyclic aromatic hydrocarbons, chlorinated pesticides and polychlorinated dibenzo-p-dioxins and dibenzofurans in 
solid wastes, Journal Chromatogrraphy A, 774, 203-211.

Rossiter, D.G., 2007. Classification of urban and industrial soils in the world reference base for soil resources, Journal of Soils andSediments, 7, 96-100.

Sicre, M.A., Marty, J.C., Saliot, A., Aparicio, X., Grimalt, J. ve Albaiges, J., 1987. Aliphatic and aromatic hydrocarbons in different sized aerosols over the mediterranean sea: occurrence and origin, Atmosphere Environment, 21, 2247-2259.

Soclo, H.H., Garrigues, P.H. ve Ewald, M., 2000. Origin of Polycyclic Aromatic Hydrocarbons (PAHs) in Coastal Marine Sediments, Case Studies in Cotonou (Benin) and Aquitaine (France) Area, Marine Pollution Bulletin, 40, 387-396.

Tiller, K.G., 1992. Urban soil contamination in Australia, Australian Journal of Soil Research, 30, 937-957.

TKKY, 2010. "27605 say1lı 08.06.2010 tarihli Toprak Kirliliği Kontrolü ve Noktasal Kaynaklı Kirlenmiş Sahalara Dair Yönetmelik (TKKY 2010/27605).

Trapido, M., 1999. Polycyclic aromatic hydrocarbons in Estonian soil: contamination and profiles, Environmental Pollution, 105, 67-74.

Wang, Z., Chen, J.., Qiao, X.., Yang, P., Tian, F. ve Huang, L., 2007. Distribution and sources of polycyclic aromatic hydrocarbons from urban to rural soils: a case study in Dalian, China, Chemosphere, 68, 965-971.

Wilcke, W., 2000. Polycyclic aromatic hydrocarbons (PAHs) in soil - a review, Journal of Plant Nutrition and Soil Science, 163, 229-248.

Wilcke, W., Krauss, M., Safronov, G., Fokin, A.D. ve Kaupenjohann, M., 2005. Polycyclic aromatic hydrocarbons (PAHs) in soils of the Moscow region concentrations, temporal trends, and smallscale distribution, Journal of Environmental Quality, 34, 1581-1590.

Witt, G., 1995. Polycyclic aromatic hydrocarbons in water and sediment of the Baltic sea, Marine Pollution Bulletin, 31, 237-248.

Zhang, Y., Schauer, J.J., Zhang, Y., Zeng, L., Wei, Y., Liu, Y. ve Shao, M., 2008. Characteristics of particulate carbon emissions from real-world Chinese coal combustion, Environmental Science and Technology, 42, 5068-5073. 